\title{
Mitigation of Inrush Current in Three Phase Power Transformer by Prefluxing Technique
}

\author{
Pradeep J.Kotak, P. S. Verma, Atul D. Tekade, S. B. Warkad
}

\begin{abstract}
Transformers are major component for electrical energy transfer in power system. Sta $\neg$ bility and security of the transformer protection are important to system operation. At the time of transformer energization, a high current will be drawn by the transformer. The mentioned current is called transient inrush current and it may rise to ten times the nominal full load current of transformer during operation. Energization transients can produce me-chanical stress to the transformer, cause protection system malfunction and it often affects the power system quality and may disrupt the operation of sensitive electrical loads such as computers and medical equipment connected to the system. Re $\neg$ duction and the way to control of energization transient currents have become im-portant concerns to the power industry for engineers. One of the methods to reduce inrush current is use of point on wave switching at the time transformer is initially connected to supply. It is called controlled switching or point-on-wave switching. In the point on wave switching, the energization of three phases is controlled ac-cording to the residual flux which remains in the transformer. Conven $\neg$ tionally, controlled switching or point on wave switching was the method being used to counter this problem, but this method required the knowledge of residual fluxes of transformer before energization which is quite tedious to get. So a technique has been pro-posed to mitigate inrush current in three phase transformer, by a process called pre-fluxing. After setting the in-itial fluxes of transformer it is energized by conventional controlled switching. A system of power transformer of specified rating is simulated in MATLAB simulink and results were obtained. This Paper describes the mod-eling of inrush current of 3-phase, $300 \mathrm{MVA}, 11 / 400 \mathrm{KV}$, $50 \mathrm{~Hz}$ transformer, and mitigation of inrush current with both techniques using point on wave switching and prefluxing. The simulation is done in MATLAB..
\end{abstract}

Keywords : Filter, Harmonics, Inrush current, MATLAB, Point-on-wave switching, prefluxing

Revised Manuscript Received on October 15, 2019.

* Correspondence Author

Pradeep J.Kotak, Assitant Professor, Department of Electrical Engineering, P. R. Pote (Patil) College of Engineering \& Management, Amravati, India E-mail: pradeepkotak5@gmail.com

P. S. Verma, Assitant Professor, Department of Electrical Engineering, P. R. Pote (Patil) College of Engineering \& Management, Amravati, India E-mail: pankh4321@gmail.com

Atul D. Tekade, Assitant Professor, Department of Electrical Engineering, P. R. Pote (Patil) College of Engineering \& Management, Amravati, India E-mail: Atul.tekade1@gmail.com

Dr. S. B. Warkad, Professor, Department of Electrical Engineering, P. R. Pote (Patil) College of Engineering \& Management, Amravati, India

E-mail:sbwarkad@gmail.com

\section{INTRODUCTION}

Transformer is a static device which transforms electrical energy from one circuit to another without any direct electrical connection and with the help of mutual induction between to windings. It transforms power from one circuit to another without changing its frequency but may be in different voltage level. A transformer is a static electrical device that transfers energy by inductive coupling between its winding circuits. A varying current in the primary winding creates a varying magnetic flux in the transformer's core and thus a varying magnetic flux in the secondary winding. This varying magnetic flux induces a varying electromotive force (emf) or voltage in the secondary winding. Transformer plays vital role in the reliable operation of power system. Reliability means continuity of supply. The demand for a reliable supply of energy has increased considerably requiring nearly a no-fault operation of power systems. A transformer is a rather large and expensive unit therefore, in a competitive and fairly low margin market, utilities tend to postpone as much as possible the replacement of aged units. This inconveniently reduces the network reliability.

A transformer breakdown could have consequences on the rest of the power system and in addition the repair time of transformers is long. The costs associated with repairing a damaged transformer is very high. The number of transient situations is believed to increase in a distributed power generation regime. A wind farm will be extensively exposed both to switching and lightning over-stresses. The understanding and prediction of these situations can result in better protection schemes and integration of power transformers in the network. Hazardous operations like inrush currents, overvoltage, internal resonances, and lightning impulse stresses manifest as electromagnetic transients and are usually difficult to accurately predict. Also, outages of transformers can interrupt the power supply for considerable durations. Inrush currents are instantaneous currents flowing in the transformer primary circuit when it is energized. They are normally of short duration, usually of the order of several seconds 
[1].

Even though they cannot be eliminated, it can be possible to limit and reduce them to a harmless state. High inrush currents can result in voltage dips and tripping of differential current relays both leading to a power quality reduction. Some providers have installed synchronized breakers to migrate high inrush currents, but this practice generally results in higher overvoltage and increases the risk of resonances[2]. The trend of increased short circuit capacity and reduced losses in power systems intensifies the inrush current problem and makes the proper setting of relays more difficult.

\section{2T PROBLEM STATEMENTS}

In recent years, various protection systems for transformers, based on the differential relaying, were developed. Various techniques based on complex circuit or microcomputers are proposed to distinguish inrush current However, the transformer still must bear with large electromagnetic stress impact caused due to the inrush current Due to these inrush current or the distortion in the current the harmonic contain of the system continuously goes on increasing and therefore the system stability decreses, also in power transformer the inrush current is major problem, so it is very necessary to reduce these inrush current. For to reduce these inrush current there are various techniques which we will discuss in this paper. One of the most recent \& important technique on which we are focusing in this paper is the Prefluxing technique. This strategy of prefluxing is used to mitigate inrush current of a three phase two winding transformer[7].In the model used,"prefluxing" phenomena is used to mitigate inrush current of three-phase two winding power transformer. Means it presented an inrush current reduction strategy which sets the residual flux of a three-phase transformer to a large magnitude and specific polarity in a method known as prefluxing and then energizes the transformer at a specified system voltage angle based on the flux polarity. This strategy has advantages over some of the presently suggested reduction strategies, including removing the need for residual flux measurements during transformer de-energization.

\section{LITERATURE REVIEW}

The inrush phenomenon was known to people from years when the transient behaviour of R-L circuits was studied. The studies related to magnetic materials, B-H curves, saturation, etc. enabled scientists to understand the concept in a better way.

In November 2009 Asghar F.F.A.done the mitigation of inrush current of power transformer by point on wave switching method. At the time of transformer energization, a high current will be drawn by the transformer. The mentioned current is called transient inrush current and it may rise to ten times the nominal full load current of transformer during operation. Energization transients can produce mechanical stress to the transformer, causes protection system malfunction and it often affect the power system quality and may disrupt the operation of sensitive electrical loads such as computers and medical equipment connected to the system. Reduction and the way to control of energization transients currents have become important concerns to the power industry for engineers. One of the methods to reduce inrush current is use of point on wave switching at the time transformer is initially connected to supply. This paper discusses the simulations and the experimental results on a three-phase transformer for reduction of inrush currents. An electronic three-phase switching controller has been designed and some thyristors were used for switching power to the transformers.

In January 2012 Douglas I. Taylor, Joseph D. Law, Brian K. Johnson, and Normann Fischer proposed prefluxing technique to mitigate inrush in single phase transformer. The idea was slightly different, instead of injecting power frequency voltage to tertiary winding, a dc voltage, i.e. a dc flux is injected in the phase of a transformer just before the instant of energization. In other words, it was a novel technique to set the transformer residual flux. The flux was set near saturation region, so it makes the process independent of the flux the core was carrying after the transformer was switched off before. Once the flux is set, the rest of the process is same as that of controlled switching. Researchers are still working on this phenomenon and trying to extend it for three phase transformers with higher ratings[7].

\section{AIM OF THE PAPER}

To minimize the peak of inrush current in three phase two winding transformer and obtained it to the steady state value, also to remove the transient component of flux in the core, there are several methods. In this paper, two different strategies of mitigation of inrush current in power transformer like Point on Wave technique and Prefluxing technique are modeled \& compared. In Point on Wave, circuit breaker is closed according to flux polarity in core. In prefluxing, first set flux using prefluxing device and then close circuit breaker according to that flux polarity. 


\section{METHODOLOGIES}

In recent years, various protection systems for transformers, based on the differential relaying, were developed. Various techniques based on complex circuit or microcomputers are proposed to distinguish inrush current and fault current. However, the transformer still must bear with large electromagnetic stress impact caused due to the inrush current. The main factors affecting the magnetizing inrush current are POW voltage at the instant of energization, magnitude and polarity of remanent flux, total resistance of the primary winding, power source inductance, air-core inductance between the energizing winding and the core, geometry of the transformer core, and the maximum flux carrying capability of the core material. From past years, many techniques have used to mitigate inrush current for example, point on wave switching, pre-insertion of resistance in primary of transformer, injection of voltage in tertiary winding etc.The main most popular method to mitigate inrush current in transformer is point- on-wave switching. This paper describe that how to mitigate inrush current by point- on-wave switching \& also describes a new method to mitigate inrush current which called Prefluxing.

\subsubsection{Point on Wave Switching Technique}

This strategy closes all three phases together at an optimum point for the residual flux pattern. It does not require independent pole breaker control, but requires knowledge of the residual flux in all three phases and the residual flux magnitudes in two phases are high and follow the most traditional residual flux pattern. These closings are chosen as part of an inrush current reduction strategy for the three phase transformer that enables the use of the three pole CBs.

\subsubsection{Prefluxing Technique}

This paper presented an inrush current reduction strategy which sets the residual flux of a three-phase transformer to a large magnitude and specific polarity in a method known as prefluxing and then energizes the transformer at a specified system voltage angle based on the flux polarity. This strategy has advantages over some of the presently suggested reduction strategies, including removing the need for residual flux measurements during transformer de-energization[7].

The prefluxing device that sets the flux of the transformer is simple in form and flexible to apply to any range of transformer sizes. In addition, the device can operate at low-voltage levels, such as the substation ac or dc supply, regardless of the voltage rating of the transformer. The results of energizing a prefluxed transformer were presented, including accounting for breaker deviation; all with inrush current levels below the transformers rating, proving the effectiveness of the reduction procedure. These greatly reduced inrush currents mean reduced stress and degradation of the transformer windings

and reduced system effects, such as harmonic over voltages or sympathetic inrush in neighboring transformers. Many techniques had been suggested to obtain residual flux on the basis of the instant of transformer was previously turned off. But it is slightly tedious process. To make a user free from knowledge of residual flux the paper proposes a new technique to set the initial fluxes of transformer as per the desired values. This is called as prefluxing.

The innovation behind the prefluxing inrush current reduction strategy lies in the prefluxing device itself. The prefluxing device capacitor is charged to a user-specified voltage and then discharged into the transformer when closing the device switch. It is necessary for the prefluxing device to set the residual flux of a transformer as high as possible to minimize the inrush current, but also to do so efficiently. The prefluxing reduction strategy is a two part process. First, the transformer residual flux is set as close as possible to its maximum achievable residual flux when the transformer is de-energized. The second part of the process controls the $\mathrm{CB}$ to energize the transformer at either an angle of 210 for positive residual flux, or 330 for negative residual flux [17]. These angles are chosen as part of an inrush current reduction strategy for three-phase transformers that enable the use of a three-pole $\mathrm{CB}$

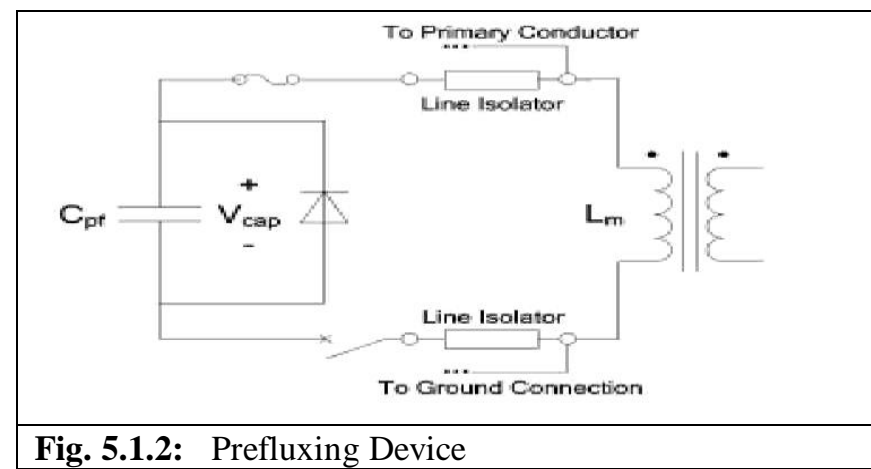

Fig. 5.1.2: Prefluxing Device

The prefluxing device is shown in Fig. 5.1.2 it consists of a capacitor, a diode, a fuse, and a switch. A charging circuit (not shown) establishes the initial voltage across the capacitor. The device is used when the transformer is isolated from the power system and connects across one of the transformer windings (the primary winding in the figure). Ideally, the highest voltage winding is used because of the reduced magnetizing current on this winding. Since the prefluxing device is only applied when the transformer is isolated and can operate at very low voltages, relatively inexpensive isolator switches can be used to connect the device to the transformer. The prefluxing device is sized to operate around the transformers magnetizing current levels, so the capacitor, diode, and fuse can be sized for a fraction of the transformer rated current. 


\section{MODELINGT IN MATLAB SIMULINK}

We have to consider one model for inrush current in transformer without using any mitigation technique, second model by using POW technique \& third model by using Prefluxing technique.

\subsection{Inrush Current Modeling of Three Phase} Two Winding Transformer

Inrush current in three phase is studied in MATLAB simulink. Here three phase power transformer having a rating of 300 MVA, 11 $\mathrm{kV} / 400 \mathrm{kV}, 50 \mathrm{~Hz}$, connected to a supply source as shown in figure 6.1. A three phase $11 \mathrm{kV}$ source connected with the transformer. The three phase transformer which is used for simulation has Y-Y connection of winding. The core magnetization resistance of three phase transformer is $154 \mathrm{ohm}$ and core magnetization inductance is $8.4 \mathrm{mH}$. The core is used with specify initial fluxes and saturated core[5][6]. Some amount of flux provide in each phases to get the value of inrush current. When the transformer energized, the flux of all three phases will increase and reached till the maximum value of flux and after that maximum value, the flux will become saturated and draw more current from source, which may be 5 to 10 time greater than rated current. The main reason of saturation of flux is residual flux. Residual flux is nothing but it is some amount of flux which remains in the transformer core at the time of de-energization of transformer. Residual flux is depending on the rating of transformer and de-energization instant. It will have different value for different rating transformer. The inrush current modeling of transformer using simulink blocks is shown below

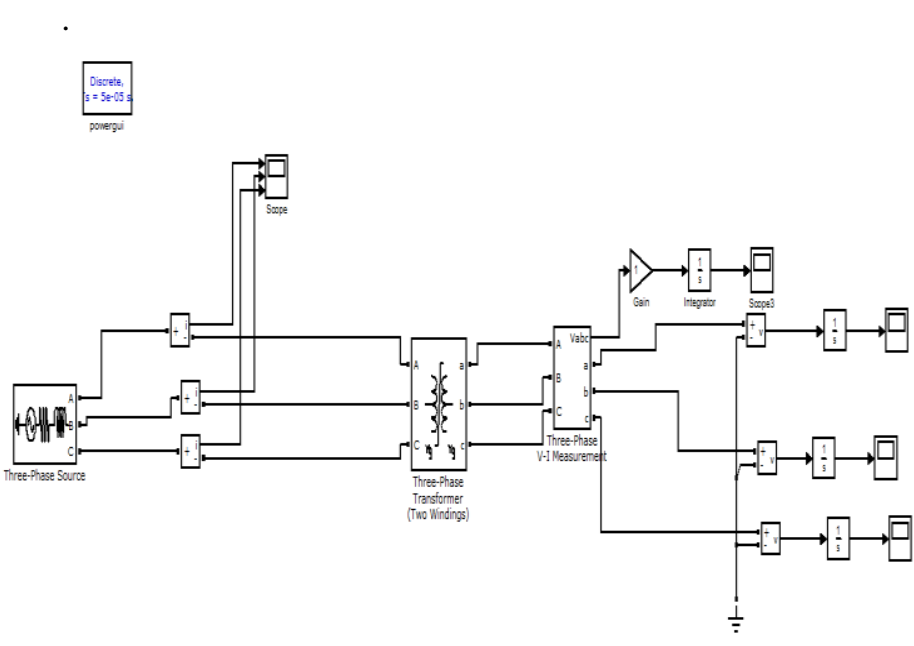

This strategy studied in MATLAB simulink environment. Three phase power transformer having a rating of $300 \mathrm{MVA}$, $11 \mathrm{kV} / 400 \mathrm{kV}, 50 \mathrm{~Hz}$, connected to a supply source as shown in figure 6.2. A three phase $11 \mathrm{kV}$ source connected with the transformer. The core magnetization resistance of three phase transformer is $154 \mathrm{ohm}$ and core magnetization inductance is $8.4 \mathrm{mH}$ the core is used with specifies initial fluxes and saturated core[5][6].

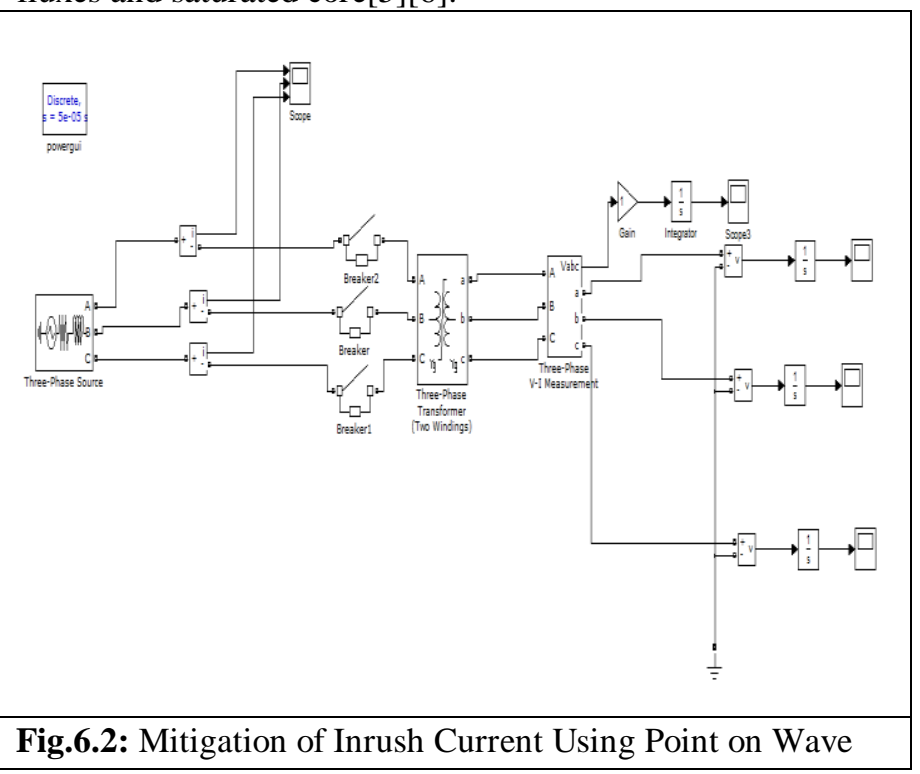

6.3 Simulink Model for mitigation of inrush current in three phase transformer Using Prefluxing method

Three phase power transformer having a rating of 300 MVA, $11 \mathrm{KV} / 400 \mathrm{KV}, 50 \mathrm{~Hz}$, connected to a supply source as shown in figure 6.3. A three phase $11 \mathrm{kV}$ source connected with the transformer. The core magnetization resistance of three phase transformer is $154 \mathrm{ohm}$ and core magnetization inductance is $8.4 \mathrm{mH}$ the core is used with specifies initial fluxes and saturated core[5][6]. 


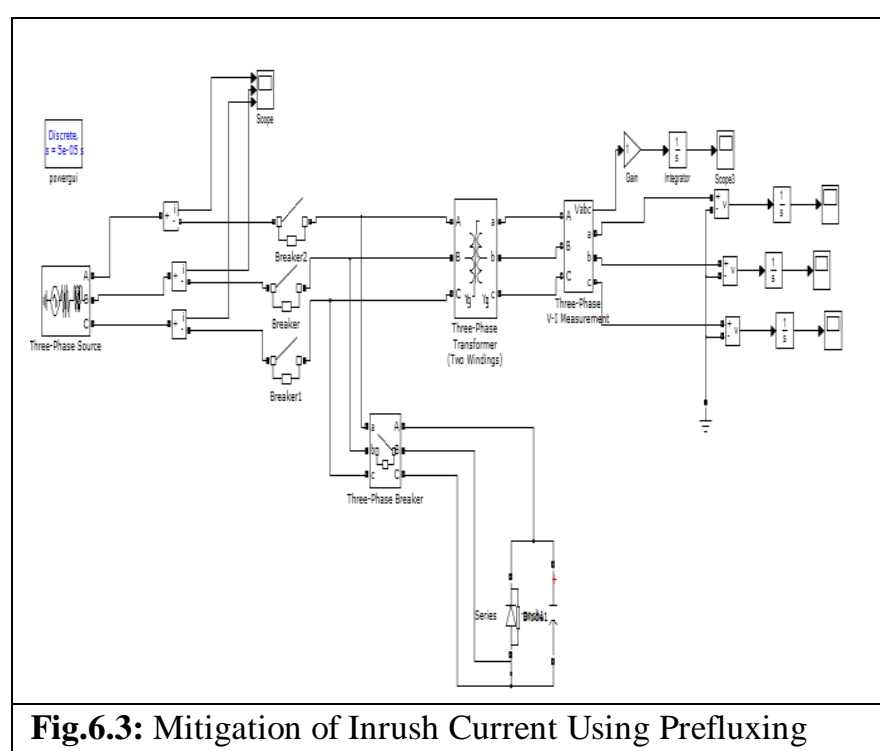

VII. SIMULATION RESULT

In this analysis we have studied nature of inrush current, the performance of three phase transformer during energization.Also we have seen the two different methods of mitigation of inrush current in three phase two winding transformer. One is point on wave switching and other is prefluxing technique. The simulation results for these methods are shown below.

\subsection{Simulation result for inrush current in three phase} transformer

In three phase transformer, asymmetrical fluxes in core caused generation of inrush current. The asymmetrical flux in core is due to the core saturation. The simulation result for current in each phase is shown in figure below

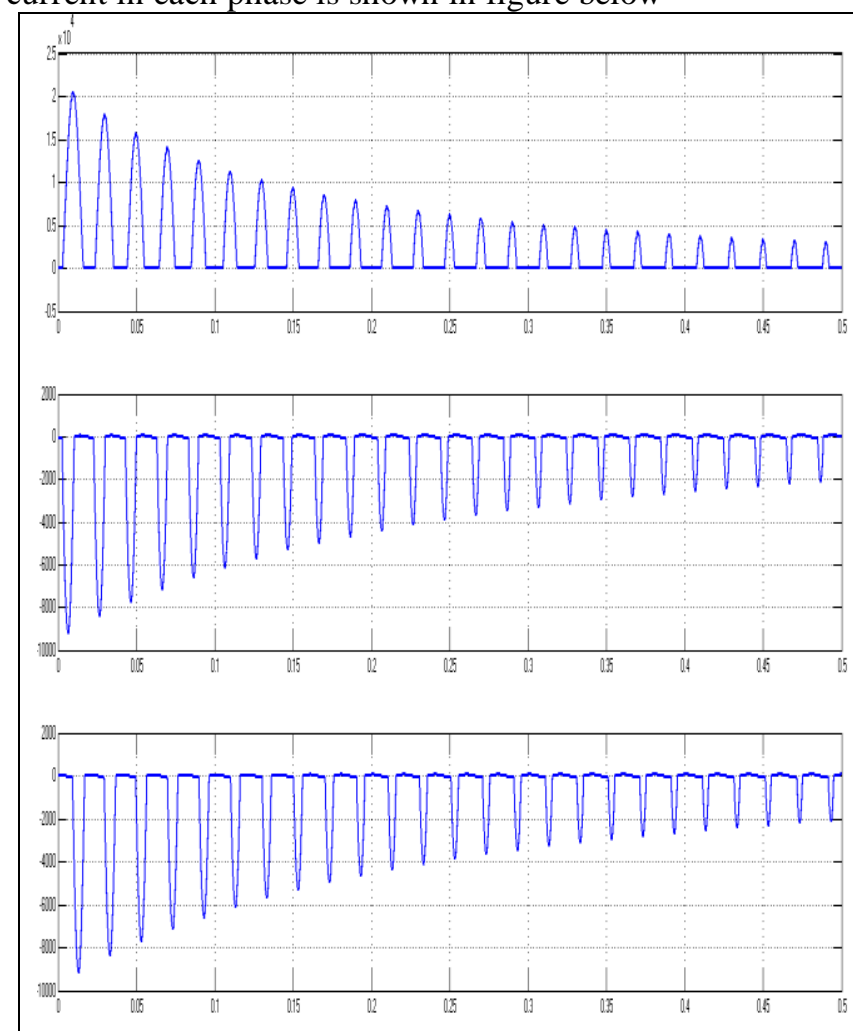

Fig. 7.1: Inrush Current in Phase A, B and C respectively

7.2 Simulation result For Mitigation of Inrush Current in Three Phase Transformer Using Point on Wave Method

In the previous analysis the inrush current in three phase transformer have been studied which is first objective of this paper. Now second objective of this paper is that to mitigate inrush current in three phase transformer. This is achieved by two different methods i.e. Point on Wave and Prefluxing. The simulation result for mitigated current in each pase is shown below.

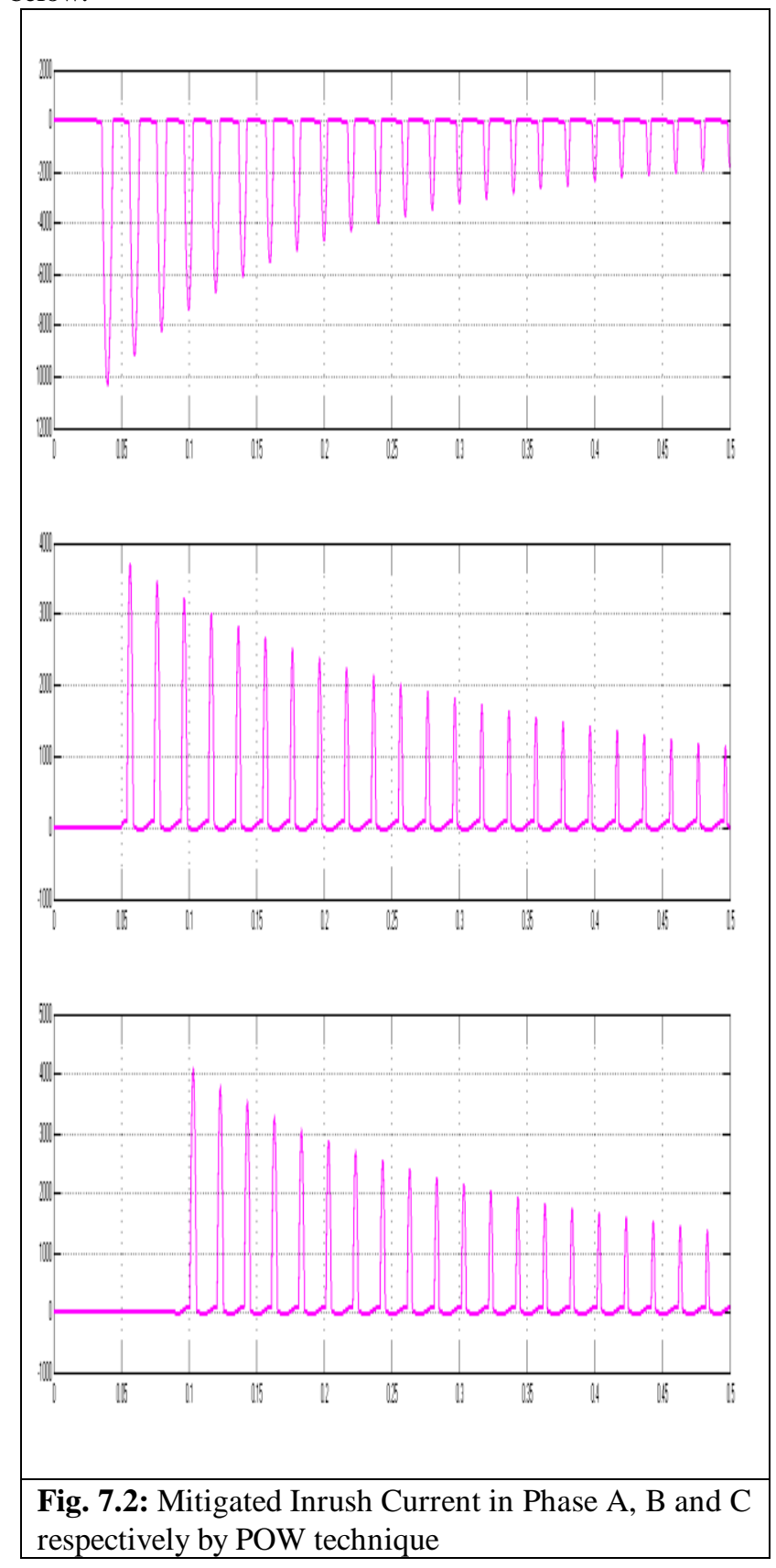

\subsection{Simulation result For Mitigation of Inrush Current in Three Phase Transformer Using Prefluxing Teacnique}

The prefluxing reduction strategy is a two part process. First the transformer's residual flux is set as close as possible to its maximum achievable residual flux with either a positive or negative polarity when the transformer is de-energized. The second part of the process controls the $\mathrm{CB}$ to energize the transformer. The simulation result for mitigated current in each pase is shown below.

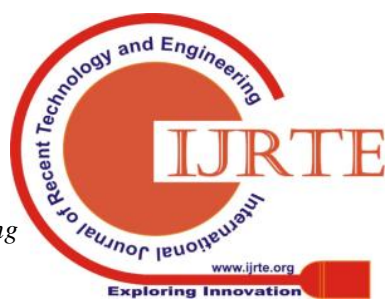




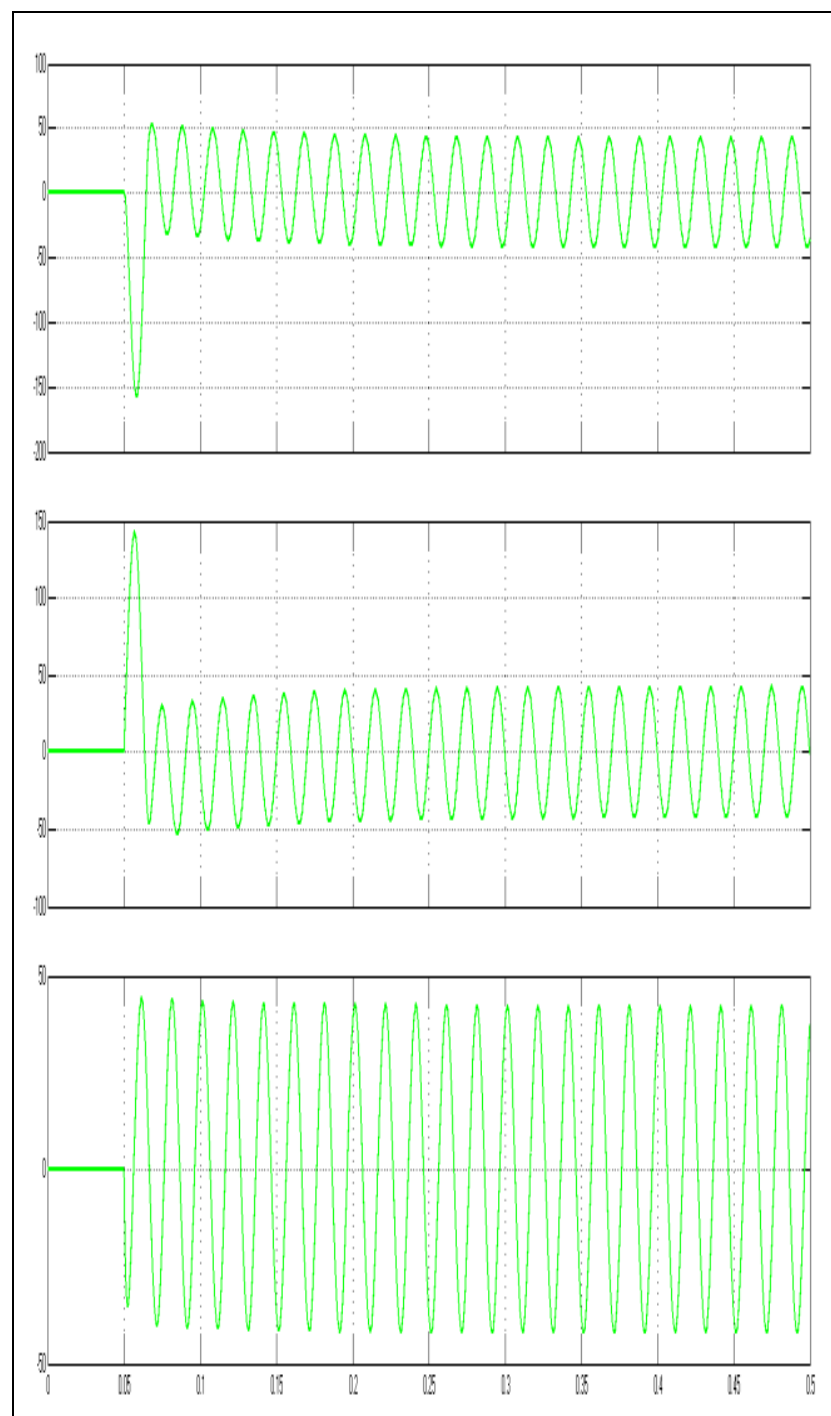

Fig. 7.3: Mitigated Inrush Current in Phase A, B and C respectively by Prefluxing technique

\section{COMPARATIVE ANALYSIS BETWEEN VALUES OF INRUSH CURRENT IN POINT ON WAVE METHOD AND PREFLUXING METHOD}

\begin{tabular}{|c|l|l|l|}
\hline & \multicolumn{1}{|c|}{ Phase } & Phase B & $\begin{array}{l}\text { Phase } \\
\text { C }\end{array}$ \\
\hline Inrush Current & $20476 \mathrm{~A}$ & $\begin{array}{l}9238.56 \\
\mathrm{~A}\end{array}$ & $\begin{array}{l}9180 . \\
38 \mathrm{~A}\end{array}$ \\
\hline $\begin{array}{l}\text { Mitigated Inrush } \\
\text { Current By Using POW } \\
\text { Technique }\end{array}$ & $10341 \mathrm{~A}$ & $3710 \mathrm{~A}$ & $\begin{array}{l}4065 \\
\mathrm{~A}\end{array}$ \\
$\begin{array}{c}\text { Mitigated Inrush } \\
\text { Current By Using } \\
\text { Prefluxing Technique }\end{array}$ & $\mathbf{1 5 7 . 5 0}$ A & $\mathbf{1 4 1 . 8 6}$ A & $\mathbf{3 5 . 2 5}$ \\
$\mathbf{A}$
\end{tabular}

Table No.8.1: Comparison between Values of Inrush Current (Ampere)

In the above table the value of inrush current in Phase $\mathrm{A}$ of three phase two winding power transformer having rating of 300 MVA, $11 \mathrm{KV} / 400 \mathrm{KV}$ is 20476 Ampere. By using mitigation technique we have to reduce it. So firstly we have used POW technique due to which inrush current reduces to 10341 Ampere after that we have used Prefluxing technique which reduces the value of inrush current to value 157.50 Ampere which is very low as compared to initial inrush current.

Similarly for Phase B and Phase $\mathrm{C}$ this Prefluxing technique reduces the initial value of inrush current to very low value i.e. 141.86Ampere and 35.25 Ampere respectively.

\section{CONCLUSION}

Simulink results show that Point on Wave reduced the inrush current in three phase transformer. Also simulation results show that Prefluxing device mitigate inrush current in three phase transformer quickly. After comparing the POW technique and Prefluxing technique, it is found that the values of inrush current in transformer are mitigated, but Prefluxing technique mitigate inrush current to lowest value and hence it is a best technique to mitigate inrush current in three phase power transformer

\section{REFERENCES}

[1] Alex Reis, Jose C. de olivira, Roberto Apolonio, Herivelto S. Bronzeado, A controlled switching methodology for transformer inrush current elimination: theory and experimental validation IEEE 2011.

[2] Abbas Ketabi, Ali reza hadidi zavareh New method for inrush current mitigation using series voltage source PWM convertor for the three phase transformer 2011 2ed power electronics, Drive system and technology conference.

[3] Jone H. Brunk, and Kalus J. Frohlich, Elimination of transformer inrush currents by controlled switching- Part- 1: theoretical consideration IEEE transactions on power delivery, Vol. 16, No. 2, April 2001.

[4] Jone H. Brunk, and Kalus J. Frohlich, Elimination of transformer inrush currents by controlled switching- Part- 2: Application and performance consideration IEEE transactions on power delivery, Vol. 16, No. 2, April 2001.

[5] Nicola chiesa Power transformer modeling for inrush current calculation Doctoral theses at NTNU 2010:64.

[6] Abdolmuteb Abou-safe, Gordon Kettleborough Modeling and calculation the inrush current in power transformer Damascus Univ. Journal Vol. (21)-No. (1) 2005 .

[7] Douglas I. Taylor, Joseph D. Law, Brian K. Johnson, and Normann Fischer, Single phase transformer inrush current reduction using prefluxing.

[8] F. Fard Ali Asghar, and K. P. Basu, Ali, Reduction of three- phase transformer magnetizing inrush current by use of point on wave switching

[9] Honkui Li, Yan Li, Xi Sun, Dongxu Li, Youteng Jing Analysis of three phase power transformer winding forces caused by magnetic inrush and short circuit current IEEE conference on applied superconductivity and electromagnetic device Chengdu, china, sep. 25-27,2009.

[10] Michael B. Marz,'Harmonic Simulations for Filter Design at a Large Industrial Load" IEEE 2000 